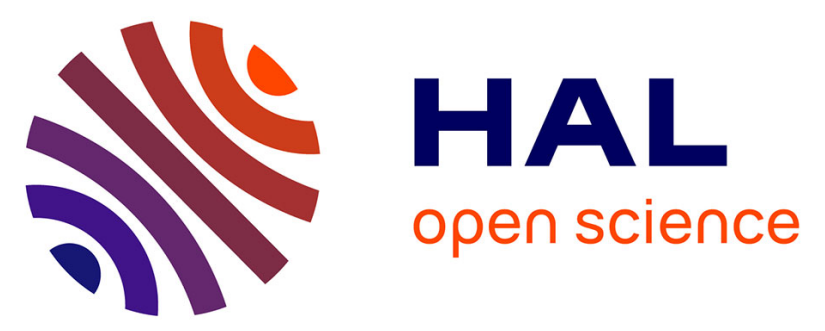

\title{
Social immunity: why we should study its nature, evolution and functions across all social systems
}

Sophie van Meyel, Maximilian Körner, Joël Meunier

\section{To cite this version:}

Sophie van Meyel, Maximilian Körner, Joël Meunier. Social immunity: why we should study its nature, evolution and functions across all social systems. Current Opinion in Insect Science, 2018, 28, pp.1-7. 10.1016/j.cois.2018.03.004 . hal-02117945

\section{HAL Id: hal-02117945 \\ https://hal-univ-tours.archives-ouvertes.fr/hal-02117945}

Submitted on 20 May 2020

HAL is a multi-disciplinary open access archive for the deposit and dissemination of scientific research documents, whether they are published or not. The documents may come from teaching and research institutions in France or abroad, or from public or private research centers.
L'archive ouverte pluridisciplinaire HAL, est destinée au dépôt et à la diffusion de documents scientifiques de niveau recherche, publiés ou non, émanant des établissements d'enseignement et de recherche français ou étrangers, des laboratoires publics ou privés. 
1 Social immunity: Why we should study its nature, evolution and

2 functions across all social systems

3 Short title: The group-living framework of social immunity

4 Sophie Van Meyel ${ }^{1 *}$, Maximilian Körner ${ }^{2 *}$, Joël Meunier ${ }^{1 \#}$

$5{ }^{1}$ Institut de Recherche sur la Biologie de I'Insecte, UMR 7261, CNRS, University of Tours, Tours,

6 France

$7 \quad{ }^{2}$ Institute of Organismic and Molecular Evolutionary Biology, Johannes-Gutenberg University of

8 Mainz, Mainz, Germany

$9 \quad{ }^{*}$ Authors contributed equally to the work

10 \#Corresponding author: Joël Meunier 


\section{Highlights}

12 - Social immunity offers protection against pathogens in group living species

13 - Mostly studied in eusocial insects, it can be found in many social systems

14 - Studying its presence in more non-eusocial systems would provide major benefits

- It would help deciphering evolutionary pathways of individual and social immunity

- It would help better understanding the roles of pathogens in social evolution 


\section{Abstract}

18 Mounting defences against pathogens is a necessity for all animals. Although these defences have long been known to rely on individual processes such as the immune system, recent studies have emphasized the importance of social defences for group-living hosts. These defences, called social

21 immunity, have been mostly studied in eusocial insects such as bees, termites and ants, and include, for instance, mutual cleaning and waste management. Over the last few years, however, a growing number of works called for a broader exploration of social immunity in non-eusocial species. In this review, we summarise the rationales of this call and examine why it may provide major insights into our current understanding of the role of pathogens in social evolution. We start by presenting the original conceptual framework of social immunity developed in eusocial insects and shed light on its importance in highly derived social systems. We then clarify three major misconceptions possibly fostered by this original framework and demonstrate why they made necessary the shift toward a broader definition of social immunity. Because a broader definition still needs boundaries, we finally present three criteria to discriminate what is a form of social immunity, from what is not. Overall, we argue that studying social immunity across social systems does not only provide novel insights into how pathogens affect the evolution of eusociality, but also of the emergence and maintenance of social life from a solitary state. Moreover, this broader approach offers new scopes to disentangle the common and specific anti-pathogen defences developed by eusocial and non-eusocial hosts, and to better understand the dependent and independent evolutionary drivers of social and individual immunity. 
During its life cycle, every animal encounters large numbers of pathogens such as viruses, protozoans, bacteria, helminths and fungi [1]. Pathogen infections often have dramatic consequences in a host, ranging from premature death to the modification of a broad set of fitness-related physiological, morphological and behavioural traits [2]. To limit the costs of pathogen infection, hosts have thus developed a multitude of defences encompassed in the term individual immunity [2-4]. In insects, these defences typically rely on physiological changes limiting pathogen development into the host body (i.e. immune system) $[2,5]$ and on behavioural processes reducing the risk of pathogen exposure and infection, for instance, by prophylactively or therapeutically consuming food sources with antipathogenic properties, a process called self-medication [4].

Over the last decades, a growing number of studies has revealed that protection against pathogens may not only rely on the defences exhibited by the host itself, but also on defences generated by its surrounding relatives [6-8]. Textbook examples of this social immunity typically come from eusocial insects such as bees, ants and termites (Figure 1) [6,8-10]. One of these examples is allo-grooming, a behaviour frequently reported in eusocial insects, during which workers groom each other to remove the pathogens present on the cuticle [11]. Another example encompasses sanitary behaviours, during which workers remove food waste and/or cadavers from their colony to prevent the development of microbial pathogens, as found in many bees, ants and termites [12-15]. Social immunity can also be illustrated by social isolation, during which infected individuals leave their colony $[16,17]$ or reduce contacts to the brood $[18,19]$ to limit the transfer of pathogens to colony members. Finally, ant and termite workers frequently use self-produced secretions to sanitize the nest walls and/or the brood [20-22], which is also a common form of social immunity (for an exhaustive list of all the classical forms of social immunity, please refer to $[6,8])$. 
evolutionary scenarios on the role of social immunity in the evolution of group living. The first scenario posited that social immunity is a phenomenon that has secondarily derived from eusocial systems and thus only plays a role in the consolidation of complex, permanent and obligatory forms of group living exhibiting reproductive division of labour (thereafter called the eusocial framework) $[6,24,25]$. The other (more recent) scenario postulates that social immunity is an ancestral phenomenon that can be found in many forms of group living and thus, that social immunity also plays a key role in the early emergence and maintenance of group living from a solitary state (thereafter called the group-living framework) $[7,8]$.

In this study, we review recent empirical data across eusocial and non-eusocial (i.e. group living species that do not exhibit a eusocial organisation) insects to emphasize why it is now time to study the nature, evolution and functions of social immunity across all social systems. Specifically, we first present the origin and implications of the eusocial framework in our current understanding of anti-pathogen defences in eusocial insects. We then discuss the rationales of the recent call for a switch from a eusocial to a group living framework by shedding light on three major misconceptions that can be fostered by the eusocial framework. In a final part, we stress that understanding social immunity requires boundaries in its definition and thus propose a newly defined group-living framework detailing three criteria that could allow discriminating what is a form of social immunity, from what is not. Overall, we argue that expanding the number of studies on social immunity in a broad taxonomical spectrum of non-eusocial species would provide novel major insights into our general understanding of the common and specific solutions developed by each type of social host to counteract infections and thus, into the role of pathogens in social evolution.

\section{The eusocial framework of social immunity}

85 The eusocial framework of social immunity emerged at the beginning of the $21^{\text {th }}$ century as the result of works conducted by researchers investigating how eusocial insects limit the inherently high risks of 
pathogen exposure and transmission between colony members $[6,9,10,26]$. The central idea of this framework is that social immunity mimics the individual immunity of multicellular organisms when the unit of selection has shifted from the individual to the colony $[23,27]$. In other words, social immunity has "evolved in convergence with individual immunity to protect the entire reproductive entity (i.e. the superorganism, [28]) and maximize its fitness" [25]. Three examples typically illustrate this parallel between personal and social immunity in eusocial insects. First, wood ants, honeybees and stingless bees collect and incorporate plant resin with antimicrobial properties into their nests to limit the development of microbial pathogens [29-31], a process mimicking individuals' selfmedication process to fight an infection [32]. Second, honeybee workers can fan their wings simultaneously to increase the temperature of their hive and thereby eliminate heat-sensitive pathogens [33], a process mimicking the fever exhibited by a body to fight an infection. Finally, workers of the ant Lasius neglectus administer antimicrobial poison inside infected cocoons to prevent pathogen replication and establishment within the colony, just like the individual immune system targets and eliminates infected cells from host body [34].

The accumulation of results supporting the parallel between individual and social immunity in eusocial insects rapidly led to the adoption of the eusocial framework by researchers interested in collective defences against pathogens. This adoption then fostered the claim that social immunity is "necessary and essential to eusocial systems" [25] and thus, that social immunity should be considered as a major and unique social parameter once eusociality has emerged $[6,9,24,25]$.

\section{The limit of the eusocial framework}

One pillar of the original eusocial framework is thus that all collective defences against pathogens employed by individuals living in non-eusocial groups are not social immunity, but instead reflect nonderived defences such as communal disease defences and parental care $[24,25]$. This boundary 
and/or separate evolutionary pathways of collective defences against pathogens across group living species $[7,8]$. Moreover, this restriction to eusocial systems opened scope for several important misconceptions concerning the link between social immunity and social evolution. For instance, it might suggest that 1 ) reproductive division of labour is essential to allow the evolution of social immunity, 2) the presence of social immunity should lower investments into individual immunity in eusocial species and finally, that 3) social immunity does not have counterparts in non-eusocial species $[6,9,10,24-26]$. In the following part, we clarify these three misconceptions using recent empirical findings and demonstrate why they call for considering social immunity as a broader phenomenon that is not exclusive to eusocial species $[7,8]$.

\section{On the importance of reproductive division of labour}

One misconceptions possibly fostered by the eusocial framework is that the direct fitness costs of performing social immunity are so high for a donor individual that they should prevent the evolution of social immunity in groups where the donors' fitness relies on their own reproduction. In other words, the net benefits of performing social immunity should only be present in groups where donor individuals forego personal reproduction, i.e. in eusocial species with reproductive division of labour [25]. The first issue with this prediction is that it neglects that some forms of social immunity are not only unlikely to provide significant fitness costs to donors (e.g. the use of self-produced secretion to sanitize the nest, the removal of fresh corpses from the nest [6]), but may also provide direct benefits to donor individuals. These direct benefits have been recently revealed in allogrooming, a textbook example of social immunity $[6,8]$. This behaviour has long been thought to be exclusively costly for donor individuals, because it increases their risk of being exposed to the pathogens present on the recipient individuals. In an elegant study conducted in the ant Lasius neglectus, however, Konrad et al [35] demonstrated that allogrooming provides direct benefits to both recipients and donors, as it allows donors to prime their own immune system and thus boost their defences against future pathogen exposure. Interestingly, a follow-up study recently showed that these direct benefits are 
pathogen-specific in that workers immune-primed with one type of pathogen preferentially direct their future allogrooming behaviours toward individuals infected with the same compared to a different pathogen [36].

The second issue with this prediction is that it overlooks the central role of kin selection in the evolution of some extreme forms of social immunity and neglects the fact that kin selection also operates in groups of individuals undergoing personal reproduction [37]. This central role can be illustrated by the self-exclusion of infected workers (figure 1), another textbook example of social immunity reported in ants and bees $[16,17]$. This behaviour reflects that infected workers leave their nest to die alone and thereby limit the infection of their colony members. The evolution of such a behaviour typically relies on kin selection, as it becomes adaptive only if it allows the genes of the sacrificed individual to be passed on to the next generation by one or more of the saved group members, i.e. only if the benefactor and the beneficiaries are genetically related. Based on the same reasoning, such a sacrificial behaviour could in principle evolve in subsocial (family) groups if the selfexclusion of infected offspring significantly improves the reproduction of their related siblings. Whether such sacrifices occur in non-eusocial species is, however, unexplored so far. Overall, social immunity is thus not necessarily associated with net fitness costs for donor individuals and it is therefore possible for social immunity to evolve in group-living species without reproductive division of labour.

\section{On the relaxed selection on individual immunity in eusocial species}

A second misconception possibly fostered by the eusocial framework is that the emergence of social immunity should relax selection on individual immunity and thus, that individual immunity should be less efficient and/or involve a lower number of genes in eusocial compared to non-eusocial species $[38,39]$. The interest of this prediction resided in the fact that it was relatively easy to test empirically. Unfortunately, the results were at odds with this prediction. On one hand, physiological studies showed that antimicrobial peptides (a component of individual immunity) are more effective in 
eusocial compared to solitary sister species in bees [40] and trips [41]. On the other hand, the recent accumulation of genomic studies comparing insects with different levels of social organization reports no general association between eusociality and the number and/or expression of immune-related genes across ants, bees and termites (reviewed in [42]). Hence, shifting the unit of selection from individual to superorganism may not affect the selection pressures exerted on individual immunity [43]. Interestingly, this apparent absence of a general link between individual and social immunities suggests that the emergence of social immunity does not reduce, but instead complements individual defences against pathogens.

\section{On the absence of social immunity in non-eusocial species}

A third misconception possibly fostered by the eusocial framework is that social immunity is exclusive to eusocial species. A recent study, however, revealed that 11 of the 30 anti-pathogen defences found in eusocial insects and classically considered as forms of social immunity [6] can also be found in noneusocial insects [8] (see also [7]). For instance, the use of self-produced components with antimicrobial properties as colony material is not only present in ants and termites $[29,44]$, but has been reported in nests of the wood cockroach Cryptocercus punctulatus, the European earwig Forficula auricularia and the Burying beetle Nicrophorus vespilloides [45-47]. Sanitary behaviours consisting in the removal of waste and feces material from the colony can also be found in several non-eusocial species with high nest fidelity (reviewed in [48]), such as the subsocial cricket Anurogryllus muticus [49]. Finally, allogrooming is a behaviour frequently observed in arthropod species where parents remain with juveniles after egg hatching (e.g. [50,51]), even if its role against pathogen infection needs to be further explored.

Whereas (at least) some forms of social immunity can be present in non-eusocial insects, it is also important to stress that (at least) some forms of social immunity are not present in all eusocial insects. For instance, queens of the pharaoh ant Monomorium pharaonic and the wood ant Formica paralugubris surprisingly prefer habitats contaminated with a pathogenic fungus to establish their 
colony [52,53], whereas the avoidance of contaminated areas is classically considered as a form of social immunity in eusocial insects [6]. Similarly, experimental exposure to pathogen spores did not trigger higher levels of allogrooming between workers in the ants Formica selysi and Myrmica rubra [11,54], and co-founding queens of the ant Lasius niger perform only very little allogrooming and did not exhibit a better resistance against pathogens when compared to solitary queens [55]. The claim derived from the eusocial framework and stating that social immunity is "necessary and essential to protect the entire reproductive entity and maximize its fitness" [25] should therefore be taken with caution. Arguably, social immunity encompasses a great diversity of forms $[6,8]$, so that the absence of evidence for one form of social immunity should not be considered as an evidence for the absence of any form of social immunity. Nevertheless, the above findings warn us on the risk to overinterpreting the expression of certain behaviours as social immune responses on the sole basis that they are present in a eusocial species.

\section{What is and what is not a form of social immunity?}

The shift from a eusocial to a group-living framework has recently generated some confusion on the boundaries of social immunity, which in turn blurred our general view of its nature, evolution and function across species. Here, we clear up this confusion by proposing a newly defined group-living framework detailing three criteria that can be used to determine whether a given defence is a form of social immunity. First, this defence should help recipient individuals to reduce their risks of infection by pathogens, which refers to anything that can produce a disease such as viruses, bacteria, protozoa, prion, fungus and helminths. This encompasses all the potential steps of an infection, which include direct contact to a pathogen, penetration, development and replication of pathogens into the recipients' body and ultimately infection-derived death of the host $[6,8]$. The second criterion is that donors and at least some of the recipients should belong both to the same species and to the same social group. This excludes, for instance, all behaviours and collective processes during which 
individuals from one species provide anti-pathogen defences to individuals from another species, as

211

212

213

214

215 commonly reported in the context of symbiosis and cleaning symbiosis in cleaner fishes [56]. Finally, the third criterion is that the defence should be "at least partly" selected for the anti-pathogen benefits it provides to the recipients. This stresses that social immunity is a target of selection and cannot be a simple by-product of individual immunity. This criterion excludes all individual defences that are either passively enhanced by group living (e.g. herd immunity [57]), selfishly driven by the nearby presence of conspecific individuals (e.g. density-dependent prophylaxis [58]) or that only happens to limit the risk of infection of solitary individuals encountered during a life cycle, such as during mating and/or competitive events. This third criterion also clarifies the rationale to separate the nomenclature between individual and social immunity.

Overall, these three criteria can be fulfilled 1) when group living is permanent, obligatory, temporary and/or facultative and 2) in a broad range of species ranging from insects and arachnids, over birds and fishes, to mammals and social microbes $[7,8]$. Importantly, this absence of a dichotomy between eusocial and non-eusocial systems emphasizes that similar selection pressures are likely to have driven the evolution of comparable forms of social immunity across group living species. For instance, the evolution of the spread of feces with antimicrobial properties on nest walls by eusocial workers in termites [44] is very likely to have evolved under the same selection pressures that the ones selecting for the spread of feces with antimicrobial properties on nest walls by juveniles in family units of burying beetles and earwigs [45,59]. To summarize, social immunity can be defined as "any collective or personal mechanism that has emerged and/or is maintained at least partly due to the anti-pathogen defence it provides to other homospecific group members", which is an edited definition of social immunity previously formulated by Meunier [8].

\section{Conclusion}


In this review, we emphasized that individuals living either in facultative/temporary groups or in obligatory/permanent colonies can all perform defences against pathogens that may not only help themselves, but also their group members. The presence of these defences in such a large diversity of social systems recently made necessary the shift from a eusocial to a broad conceptual framework of social immunity $[6-8,24,25]$. This shift has generated novel works using the term 'social immunity' in a few subsocial insects such as the European earwig (e.g. $[45,60,61])$ and the burying beetle (e.g. $[59,62,63])$. Here, we claim that it is crucial to expand these first works to a taxonomically broader number of non-eusocial species. The resulting studies would first allow us to disentangle whether the selection pressures favouring the emergence of social immunity have either secondarily evolved to limit the inherently high risk of pathogen exposure in species with an obligatory and permanent social life (i.e. some forms of social immunity derive from eusociality), or whether they remained constant after the evolutionary shift from solitary to group living (i.e. social immunity is an ancestral process) $[7,8]$. Interestingly, it would also allow testing an alternative evolutionary scenario positing that the general risk of pathogen exposure for a solitary individual could have selected for the emergence of group living in order to obtain an additional line of defence such as social immunity [64]. Second, a taxonomically broader number of studies on social immunity would allow us exploring the potential trade-off between social and individual immunity across group-living species [65] and thus shed light on the dependent or independent evolutionary drivers of these two lines of anti-pathogen defences across animals. For instance, it would allow us to address questions such as whether certain types of pathogens are more likely to apply selection pressure onto individual instead of social immunity, or whether these two lines of defences necessarily trade-off across social systems [65]. Finally, noneusocial species could offer experimental opportunities that are not available in eusocial species and thus allow exploration of novel factors possibly underlying the expression of social immunity. For instance, a recent study in the European earwig allowed to demonstrate that the recent (but not prolonged!) social isolation of group-living adults induces a stress that specifically lowers their resistance against pathogens, whereas comparing the effects of pathogens on necessarily-newly 
isolated and non-isolated individuals is often used to test for the occurrence of social immunity in eusocial insects [61]. Overall, adopting the group living framework thus opens new perspectives to explore and better understand the common and specific solutions developed by each type of social host to counteract infections and thus, to improve our general understanding of the role of pathogens in the evolution of all forms of social life. Given the comparatively large amount of works on social immunity in eusocial insects, it is now time to further explore social immunity in a larger and taxonomically broader number of non-eusocial species.

\section{Conflict of interest statement}

267 The authors declare no conflict of interest.

\section{Acknowledgments}

269 We thank Sylvia Cremer, Raphaël Boulay, Franck Dedeine, Marlène Goubault, Sandra Steiger and an 270 anonymous reviewer for their insightful comments on a previous or the current version of this 271 manuscript. This research has been supported by a research grant from the French Ministry of 272 Research (to SVM), from the German Science Foundation (DFG; ME4179/3-1 to JM) and from the Fyssen Foundation (to JM). 


\section{References}

1. Lu HL, St. Leger RJ: Insect Immunity to Entomopathogenic Fungi. Adv Genet 2016, 94:251285.

2. Siva-jothy MT, Moret $\mathrm{Y}$, Rolff J: Insect immunity : An evolutionary ecology perspective. $A d v$ In Insect Phys 2005, 32:1-48.

3. Schmid-Hempel P: Evolutionary parasitology. Oxford University Press; 2014.

4. de Roode JC, Lefèvre T: Behavioral immunity in insects. Insects 2012, 3:789-820.

5. Hillyer JF: Insect immunology and hematopoiesis. Dev Comp Immunol 2016, 58:102-118.

6. Cremer S, Armitage SAO, Schmid-Hempel P: Social immunity. Curr Biol 2007, 17:R693-702.

7. Cotter SC, Kilner RM: Personal immunity versus social immunity. Behav Ecol 2010, 21:663668.

8. Meunier J: Social immunity and the evolution of group living in insects. Philos Trans $R$ Soc $B$ Biol Sci 2015, 370:20140102.

9. Schmid-Hempel P: Parasites in social insects. Princeton University Press; 1998.

10. Wilson-Rich N, Spivak M, Fefferman NH, Starks PT: Genetic, individual, and group facilitation of disease resistance in insect societies. Annu Rev Entomol 2009, 54:405-23.

11. Reber A, Purcell J, Buechel SD, Buri P, Chapuisat M: The expression and impact of antifungal grooming in ants. J Evol Biol 2011, 24:954-964.

12. Zeh JA, Zeh AD, Zeh DW: Dump material as an effective small-scale deterrent to herbivory by Atta cephalotes. Biotropica 1999, 31:368-371.

13. Hart AG, Bot ANM, Brown MJF: A colony-level response to disease control in a leaf-cutting ant. Naturwissenschaften 2002, 89:275-277.

14. Ulyshen MD, Shelton TG: Evidence of cue synergism in termite corpse response behavior. Naturwissenschaften 2012, 99:89-93.

15. Visscher PK: The honey bee way of death: Necrophoric behaviour in Apis mellifera colonies. Anim Behav 1983, 31:1070-1076.

16. Heinze J, Walter B: Moribund ants leave their nests to die in social isolation. Curr Biol 2010, 20:249-52.

17. Rueppell O, Hayworth MK, Ross NP: Altruistic self-removal of health-compromised honey bee workers from their hive. J Evol Biol 2010, 23:1538-46.

18. Ugelvig LV, Cremer S: Social prophylaxis: group interaction promotes collective immunity in ant colonies. Curr Biol 2007, 17:1967-71.

19. Bos N, Lefèvre T, Jensen AB, D’Ettorre P: Sick ants become unsociable. J Evol Biol 2012, 25:342-51.

20. López-Uribe MM, Fitzgerald A, Simone-Finstrom M: Inducible versus constitutive social immunity: examining effects of colony infection on glucose oxidase and defensin-1 production in honeybees. Open Sci 2017, 4:170224.

21. Yek SH, Mueller UG: The metapleural gland of ants. Biol Rev 2011, 86:774-91.

22. Baracchi D, Mazza G, Turillazzi S: From individual to collective immunity: the role of the venom as antimicrobial agent in the Stenogastrinae wasp societies. J Insect Physiol 2012, 58:188-93. 
23. Cremer S, Sixt M: Analogies in the evolution of individual and social immunity. Philos Trans $R$ Soc London B Biol Sci 2009, 364:129-42.

24. Schmid-Hempel P: Parasites and their social hosts. Trends Parasitol 2017, 33:453-462.

25. Cremer S, Pull CD, Fürst MA: Social immunity: emergence and evolution of colony-level disease protection. Annu Rev Entomol 2018, 63:105-123.

26. Naug $D$, Camazine $S$ : The role of colony organization on pathogen transmission in social insects. J Theor Biol 2002, 215:427-39.

27. Masri L, Cremer S: Individual and social immunisation in insects. Trends Immunol 2014, 35:471-482.

28. Kennedy P, Baron G, Qiu B, Freitak D, Helanterä H, Hunt ER, Manfredini F, O'Shea-Wheller T, Patalano $S$, Pull CD, et al.: Deconstructing superorganisms and societies to address big questions in biology. Trends Ecol Evol 2017, 32:861-872.

29. Christe P, Oppliger A, Bancalà F, Castella G, Chapuisat M: Evidence for collective medication in ants. Ecol Lett 2003, 6:19-22.

30. Simone M, Evans JD, Spivak M: Resin collection and social immunity in honey bees. Evolution 2009, 63:3016-22.

31. Duangphakdee O, Koeniger N, Deowanish S, Hepburn HR, Wongsiri S: Ant repellent resins of honeybees and stingless bees. Insectes Soc 2009, 56:333-339.

32. de Roode JC, Lefèvre T, Hunter MD: Self-medication in animals. Science 2013, 340:150-1.

33. Starks PT, Blackie CA, Seeley TD: Fever in honeybee colonies. Naturwissenschaften 2000, 87:229-31.

34. Pull CD, Ugelvig L V, Wiesenhofer F, Grasse A V, Tragust S, Schmitt T, Brown MJ, Cremer S: Destructive disinfection of infected brood prevents systemic disease spread in ant colonies. elife 2018, 7:1-29.

35. Konrad M, Vyleta ML, Theis FJ, Stock M, Tragust S, Klatt M, Drescher V, Marr C, Ugelvig L V, Cremer S: Social transfer of pathogenic fungus promotes active immunisation in ant colonies. PLOS Biol 2012, 10:e1001300.

36. Konrad M, Pull CD, Metzler S, Seif K, Naderlinger E, Grasse A V, Cremer S: Ants avoid superinfections by performing risk-adjusted sanitary care. PNAS 2018, 201713501.

37. Kramer J, Meunier J: Kin and multilevel selection in social evolution: a never-ending controversy? F1000Research 2016, 5:776.

38. Evans JD, Aronstein K, Chen YP, Hetru C, Imler J-L, Jiang H, Kanost M, Thompson GJ, Zou Z, Hultmark D: Immune pathways and defence mechanisms in honey bees Apis mellifera. Insect Mol Biol 2006, 15:645-56.

39. Weinstock GM, Robinson GE, Gibbs R a, Worley KC, Evans JD, Maleszka R, Robertson HM, Weaver DB, Beye M, Bork $P$, et al.: Insights into social insects from the genome of the honeybee Apis mellifera. Nature 2006, 443:931-949.

40. Stow A, Briscoe D, Gillings M, Holley M, Smith S, Leys R, Silberbauer T, Turnbull C, Beattie A: Antimicrobial defences increase with sociality in bees. Biol Lett 2007, 3:422-4.

41. Turnbull C, Hoggard SJ, Gillings M, Palmer C, Stow A, Beattie D, Briscoe D, Smith S, Wilson P, Beattie A: Antimicrobial strength increases with group size: implications for social evolution. Biol Lett 2011, 7:249-52.

42. Otani S, Bos N, Yek SH: Transitional Complexity of Social Insect Immunity. Front Ecol Evol 
2016, 4:1-5.

43. Barribeau SM, Sadd BM, du Plessis L, Brown MJ, Buechel SD, Cappelle K, Carolan JC, Christiaens $\mathrm{O}$, Colgan TJ, Erler $\mathrm{S}$, et al.: A depauperate immune repertoire precedes evolution of sociality in bees. Genome Biol 2015, 16.

44. Chouvenc $T$, Efstathion CA, Elliott ML, Su N: Extended disease resistance emerging from the faecal nest of a subterranean termite. Proc R Soc B Biol Sci 2013, 280:20131885.

45. Diehl JM, Körner M, Pietsch $M$, Meunier J: Feces production as a form of social immunity in an insect with facultative maternal care. BMC Evol Biol 2015, 15:15:40.

46. Cotter SC, Kilner RM: Sexual division of antibacterial resource defence in breeding burying beetles, Nicrophorus vespilloides. J Anim Ecol 2010, 79:35-43.

47. Rosengaus RB, Mead K, Du Comb WS, Benson RW, Godoy VG: Nest sanitation through defecation: antifungal properties of wood cockroach feces. Naturwissenschaften 2013, 100:1051-9.

48. Weiss MR: Defecation behavior and ecology of insects. Annu Rev Entomol 2006, 51:635-61.

49. West MJ, Alexander RD: Sub-social behavior in a burrowing cricket, Anurogryllus muticus (De Geer). Ohio J Sci 1963, 63:19-24.

50. Mas F, Kölliker M: Differential effects of offspring condition-dependent signals on maternal care regulation in the European earwig. Behav Ecol Soc 2011, 65:341-349.

51. Thiel M: Extended parental care in marine amphipods II. Maternal protection of juveniles from predation. J Exp Mar Bio Ecol 1999, 234:235-253.

52. Brütsch T, Felden A, Reber A, Chapuisat M: Ant queens (Hymenoptera : Formicidae) are attracted to fungal pathogens during the initial stage of colony founding. Myrmecological news 2014, 20:71-76.

53. Pontieri L, Vojvodic S, Graham R, Pedersen JS, Linksvayer TA: Ant colonies prefer infected over uninfected nest sites. PLoS One 2014, 9:e111961.

54. Leclerc J-B, Detrain C: Ants detect but do not discriminate diseased workers within their nest. Sci Nat 2016, 103:70.

55. Brütsch T, Avril A, Chapuisat M: No evidence for social immunity in co-founding queen associations. Sci Rep 2017, 7:16262.

56. Hopkins SR, Wojdak JM, Belden LK: Defensive Symbionts Mediate Host-Parasite Interactions at Multiple Scales. Trends Parasitol 2017, 33:53-64.

57. Babayan SA, Schneider DS: Immunity in society: diverse solutions to common problems. PLOS Biol 2012, 10:e1001297.

58. Wilson K, Cotter SC: Density-dependent prophylaxis in insects. In Phenotypic plasticity of insects. Edited by Whitman D. CRC Press; 2009:137-176.

59. Reavey CE, Beare L, Cotter SC: Parental care influences social immunity in burying beetle larvae. Ecol Entomol 2014, 39:395-398.

60. Boos S, Meunier J, Pichon S, Kölliker M: Maternal care provides antifungal protection to eggs in the European earwig. Behav Ecol 2014, 25:754-761.

61. Kohlmeier $P$, Holländer $K$, Meunier J: Survival after pathogen exposure in group-living insects: don't forget the stress of social isolation! J Evol Biol 2016, 29:1867-1872.

62. Duarte A, Cotter SC, Reavey CE, Ward RJS, de Gasperin O, Kilner RM: Social immunity of the family: parental contributions to a public good modulated by brood size. Evol Ecol 2015, 
30:123-135

402

63. Reavey CE, Warnock ND, Garbett AP, Cotter SC: Aging in personal and social immunity: do immune traits senesce at the same rate? Ecol Evol 2015, 5:4365-4375.

64. Biedermann PHW, Rohlfs M: Evolutionary feedbacks between insect sociality and microbial management. Curr Opin Insect Sci 2017, 22:92-100.

406

407

65. Cotter SC, Topham E, Price a JP, Kilner RM: Fitness costs associated with mounting a social immune response. Ecol Lett 2010, 13:1114-23.

408 

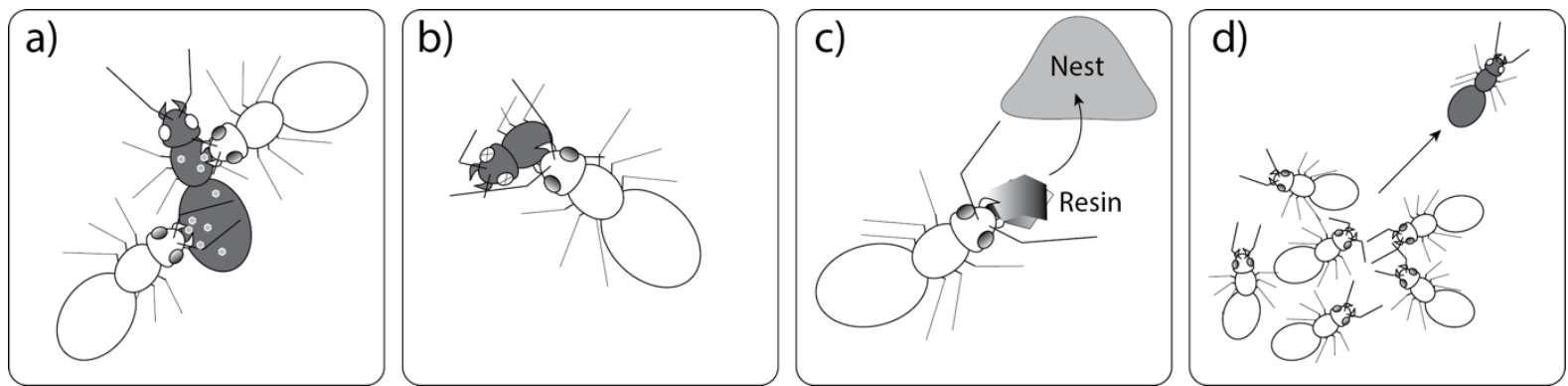

410 Figure 1 | Four classical examples of social immunity that can be found in ant colonies. (a) Two workers

411 groom an infected nestmate (grey) to remove external pathogens. (b) A worker carries a corpse (grey)

412 away from the nest. (c) A worker collects a piece of resin with antimicrobial properties and brings it

413 back to its nest. (d) An infected worker (grey) isolates itself from the group to limit the risk of pathogen spread. References can be found in $[6,8]$. 


\section{Highlighted references}

-• [25] Cremer S, Pull CD, Fürst MA: Social Immunity: Emergence and Evolution of Colony-Level Disease Protection. Annu Rev Entomol 2018, 63:105-123.

415

416

417

418

419

420

-• [34] Pull CD, Ugelvig L V, Wiesenhofer F, Grasse A V, Tragust S, Schmitt T, Brown MJ, Cremer S: Destructive disinfection of infected brood prevents systemic disease spread in ant colonies. elife 2018, 7:1-29.

- [42] Otani S, Bos N, Yek SH: Transitional Complexity of Social Insect Immunity. Front Ecol Evol 2016, 4:1-5.

- [28] Kennedy P, Baron G, Qiu B, Freitak D, Helanterä H, Hunt ER, Manfredini F, O'Shea-Wheller T, Patalano $S$, Pull CD, et al.: Deconstructing Superorganisms and Societies to Address Big Questions in Biology. Trends Ecol Evol 2017, 32:861-872.

This very interesting study discusses the concept of superorganism and its importance in our general understanding of social evolution, including disease defences.

This experimental study sheds light on a novel form of social immunity in ants. In particular, workers target infected pupae in their colony and then perforate its cuticle and administer antimicrobial poison to prevent pathogen replication from the inside. This is argued to mimic the immune system of a metazoan body that targets and eliminates infected cells.

Based on an overview of the recent comparative genomic litterature, the authors shed light on the poor support to the claim that evolutionary transition to eusociality resulted in a reduction of immunity-related genes. They also emphasize the importance to standardise the methologies 

understand the complexity of social insect immunity.

- [55] Brütsch T, Avril A, Chapuisat M: No evidence for social immunity in co-founding queen associations. Sci Rep 2017, 7:16262. eusocial insects. In particular, the authors show that co-founding queens to not survive better to pathogenes exposure compared to solitary ones. Notably, co-founding queens also expressed very little allo-grooming and trophallaxis.

-• [64] Biedermann PH, Rohlfs M: Evolutionary feedbacks between insect sociality and microbial management. Curr Opin Insect Sci 2017, 22:92-100 In this review, the authors discuss the role of microbes (including pathogens) in social evolution. In particular, they claim that pathogens could serve as promotors of social evolution by favoring cooperation between potential hosts to better fight against infections. 